\title{
Roles of the GA-mediated SPL Gene Family and miR156 in the Floral Development of Chinese Chestnut (Castanea mollissima)
}

\author{
Guosong Chen ${ }^{1,+} \oplus$, Jingtong $\mathrm{Li}^{1,+}$, Yang Liu ${ }^{1}$, Qing Zhang ${ }^{2}$, Yuerong Gao ${ }^{1}$, Kefeng Fang ${ }^{3}$, \\ Qingqin Cao ${ }^{4}$, Ling Qin ${ }^{1, *}$ and Yu Xing ${ }^{1, *}$ \\ 1 Beijing Advanced Innovation Center for Tree Breeding by Molecular Design, \\ Beijing University of Agriculture, Beijing 102206, China; cgschennuo@163.com (G.C.); \\ wangyi1314aa@163.com (J.L.); bualiuyang@163.com (Y.L.); gaoyr@cau.edu.cn (Y.G.) \\ 2 College of Plant Science and Technology, Beijing Key Laboratory for Agricultural Application and New Technique, \\ Beijing University of Agriculture, Beijing 102206, China; zhangqing@bua.edu.cn \\ 3 Beijing Collaborative Innovation Center for Eco-environmental Improvement with Forestry and Fruit Trees, \\ Beijing 102206, China; fangkefeng@126.com \\ 4 College of Biological Science and Engineering, Key Laboratory of Urban Agriculture (North China), \\ Ministry of Agriculture, Beijing 102206, China; caoqingqin@bua.edu.cn \\ * Correspondence: qinlingbac@126.com (L.Q.); xingyubua@163.com (Y.X.); Tel.: +86-10-8079-7229 (Y.X.) \\ $\dagger$ These authors contributed equally to this work.
}

Received: 4 March 2019; Accepted: 25 March 2019; Published: 29 March 2019

Abstract: Chestnut (Castanea mollissima) is a deciduous tree species with major economic and ecological value that is widely used in the study of floral development in woody plants due its monoecious and out-of-proportion characteristics. Squamosa promoter-binding protein-like (SPL) is a plant-specific transcription factor that plays an important role in floral development. In this study, a total of 18 SPL genes were identified in the chestnut genome, of which 10 SPL genes have complementary regions of CmmiR156. An analysis of the phylogenetic tree of the squamosa promoter-binding protein (SBP) domains of the SPL genes of Arabidopsis thaliana, Populus trichocarpa, and C. mollissima divided these SPL genes into eight groups. The evolutionary relationship between poplar and chestnut in the same group was similar. A structural analysis of the protein-coding regions (CDSs) showed that the domains have the main function of SBP domains and that other domains also play an important role in determining gene function. The expression patterns of CmmiR156 and CmSPLs in different floral organs of chestnut were analyzed by real-time quantitative PCR. Some CmSPLs with similar structural patterns showed similar expression patterns, indicating that the gene structures determine the synergy of the gene functions. The application of gibberellin (GA) and its inhibitor (Paclobutrazol, $\mathrm{PP}_{333}$ ) to chestnut trees revealed that these exert a significant effect on the number and length of the male and female chestnut flowers. GA treatment significantly increased CmmiR156 expression and thus significantly decreased the expression of its target gene, CmSPL6/CmSPL9/CmSPL16, during floral bud development. This finding indicates that GA might indirectly affect the expression of some of the SPL target genes through miR156. In addition, RNA ligase-mediated rapid amplification of the $5^{\prime}$ cDNA ends (RLM-RACE) experiments revealed that CmmiR156 cleaves CmSPL9 and CmSPL16 at the 10th and 12th bases of the complementary region. These results laid an important foundation for further study of the biological function of CmSPLs in the floral development of C. mollissima.

Keywords: Castanea mollissima; miR156; SPL gene family; GA; floral development; expression patterns 


\section{Introduction}

Chinese chestnut (Castanea mollissima BL.) is rich in nutrients, resistant to disease, and barren, and these features make Chinese chestnut an important ecological and economic tree species. As a monoecious plant, the proportion of female and male flowers in Chinese chestnut can reach 1:2400-4000. A large number of male flowers consume too much tree nutrition, which is one of the important reasons for the low yield of chestnut [1,2]. Therefore, exploration of the mechanism of floral development is important for regulating the ratio of female to male flowers, which might provide valuable information for solving the problem of the low chestnut yield. Floral development is mainly influenced by genetic factors and environmental conditions [3], and phytohormones have been reported to play an important role in floral development [4]. For example, in floral regulatory networks, gibberellins (GAs) are critical for the development of reproductive organs, especially for floral sex determination [5,6]. Auxin determines whether the primordium of the flower is formed during the initial process of the organ and the specificity of the flower organ formed during organogenesis [7]. Cytokinins (CKs) contribute to the sex control of Jatropha curcas [8] and have been used for many years in horticultural production practices [9]. Genes related to phytohormone biosynthesis and signaling have been identified and are reportedly involved in floral development in several species [10]. A naturally occurring male inflorescence mutation was found on a branch of a Chinese chestnut tree in the mountains near Beijing, China, with a male inflorescence length reduced from $1 / 6$ to $1 / 8$ of the wild-type male inflorescence on the same tree, and the application of exogenous $\mathrm{GA}_{3}$ partially restored the sck 1 phenotype to the wild-type phenotype [2]. Therefore, it is very important to investigate the effect of GA on floral development in chestnut by spraying the whole tree with GA and its biosynthesis antagonist, $\mathrm{PP}_{333}$.

Transcription factors (TFs) precisely coordinate gene expression by activating or inhibiting transcription in response to various endogenous and environmental signals and are usually divided into different families based on the sequences of the DNA-binding domain and other conserved motifs [11]. Plants have thousands of TF families, such as MYB, NAC (NAM, ATAF1/2, and CUC2), auxin response factors $(A R F s)$, Squamosa promoter-binding protein-like $(S P L)$, and $b H L H$, which play crucial roles in the regulation of the gene networks involved in many important developmental processes and defense responses in plants [12-16]. Among these TF families, the SPL family members are important TFs in plant floral development and have been identified in Arabidopsis [17], Populus trichocarpa [18], Betula luminifera [19], Brassica napus [20], Petunia hybrida [21], and other flowering species. SPLs are plant-specific TFs that contain a highly conserved SBP binding domain of approximately 80 amino acids, which contains two zinc finger structures and a nuclear localization signal [22,23]. Based on the important role of the SPL gene family in plant floral development, ranging from vegetative to reproductive growth [24], male sterility [25], GA synthesis [26], and floral morphogenesis [27], researchers have identified SPL genes in a growing number of species: 16 SPL genes in Arabidopsis [17], 28 SPL genes in P. trichocarpa [18], 21 SPL genes in P. hybrida [21], and 18 SPL genes in B. luminifera [19].

MicroRNAs (miRNAs) are approximately 21-23 nucleotides (nt) long, small single-strand noncoding RNAs which are encoded by endogenous genes. miRNA plays a key role in regulating gene activity at post-transcriptional levels by binding to complementary sites in target genes, causing degradation and/or translational repression of the target mRNAs [28]. miRNA functions broadly to regulate many aspects of plant development. For instance, miR160 or miR167 targets $A R F s$, which are involved in auxin or defense responses or play roles at many stages of development [14,29]; MYB TFs are antagonized by miR159 in the control of floral development and heat response or in conjunction with miR828 to modulate fiber development [12,30]; and NAC TFs, which are encoded by miR164 target genes, play roles in lateral root development, boundary specification, drought tolerance, or the immune response [13,31,32]. The majority of $S P L$ genes in many species have complementary regions of miR156, and the miR156/SPL mode of action has been shown to play a key regulatory role in many growth and development processes [33-36]. For instance, either the overexpression of csi-miR156a or the individual knockdown of one of its two target genes, CSSPL3 and CsSPL14, significantly enhances the somatic embryogenesis competence of citrus callus [37]. PvSPL4 is the target gene of the microRNA 
pvi-miR156 and controls the initiation of aerial axillary buds of switchgrass [38]. miR156 regulates Arabidopsis pollen production, fertility, and elongation of floral organs (including petals, sepals, and wafers) by inhibiting the expression of the target gene SPL2 [27].

The floral development of chestnut shows differences from those of Arabidopsis and P. trichocarpa, which are characterized by monoecism (with unisexual flowers) and large differences between male and female flowers. Therefore, it is important to study the genes related to floral development in chestnut. In this study, to systematically analyze the characteristics of the SPL genes in chestnut, the molecular structures and expression patterns of SPL genes in C. mollissima were compared with those of Arabidopsis and P. trichocarpa, and the relationship between SPL genes among different species and the role of CmSPL genes in expression regulation were examined. In addition, the effects of GA on both male and female flowers of $C$. mollissima were investigated by treating chestnut trees with GA, and the expression patterns of CmSPL and CmmiR156 during floral bud development and the GA-mediated induction of the expression of these genes were explored.

\section{Results}

\subsection{Effects of $G A$ and Its Inhibitor on the Number of Male and Female Inflorescences}

To analyze the effects of GA on floral development, GA and its inhibitor were applied to 18-year-old trees. Because the chestnut female flower undergoes differentiation outside of the bud and floral morphogenesis occurs after germination, GA and $\mathrm{PP}_{333}$ were first sprayed before the floral buds germinated in late March. The first sampling was performed once the buds turned green, and both GA and $\mathrm{PP}_{333}$ spraying and sampling were performed at 1-week intervals until the male inflorescence appeared, at which time sampling was stopped. During this period, a total of four samples, denoted Floral Bud 1 (FB1)-FB4, were obtained, and the floral bud morphology was observed, as shown in Figure 1A. The number and lengths of male and female flowers were investigated at the flowering stage, and the results are shown in Table 1 . Treatment with $100 \mathrm{mg} / \mathrm{L}$ of GA increased the number of male inflorescences on each branch and significantly reduced the ratio of female flower clusters to male inflorescences, the male inflorescence length, and the mixed inflorescence length. The GA treatment also decreased, albeit not significantly, the number of female flowers. In contrast, treatment with the GA inhibitor $\mathrm{PP}_{333}$ at a concentration of $1000 \mathrm{mg} / \mathrm{L}$ significantly increased the number of female flowers and insignificantly increased the mixed inflorescence length.

To analyze the effects of the exogenous addition of the hormone GA and the GA inhibitor $\mathrm{PP}_{333}$ on endogenous hormones, the expression levels of key genes in the GA synthesis and signaling pathways were determined (Figure 1B). Three key genes in in the GA synthetic pathway, namely, ent-kaurene synthase $(K S)$, ent-kaurene oxidase $(K O)$, and ent-kaurenoic acid oxidase $(K A O)$, and two typical genes in the GA signaling pathway, namely, DELLA and GA-insensitive drawf1 (GID1), were selected [39]. Their analysis revealed that $K S$ and GID1 gene expression showed a decreasing trend during floral bud differentiation, and no significant difference was obtained after the treatments. During $\mathrm{PP}_{333}$ treatment, $K O, K A O$, and $D E L L A$ expression was significantly decreased during the first floral bud stage, and the overall trend was downward. No significant differences were found between the control and GA treatments.

Table 1. Multiple test (LRS) results of the effects of various growth regulators on the number of male and female flowers.

\begin{tabular}{|c|c|c|c|c|c|c|c|c|}
\hline Species & $\begin{array}{l}\text { Concentration } \\
\left(\mathrm{mg} \cdot \mathrm{L}^{-1}\right)\end{array}$ & $\begin{array}{l}\text { Female } \\
\text { Flower } \\
\text { Cluster } \\
\text { /Branch }\end{array}$ & $\begin{array}{l}\text { Number of } \\
\text { Mixed } \\
\text { Inflorescences } \\
\text { /Branch }\end{array}$ & $\begin{array}{c}\text { Mixed } \\
\text { Inflorescence } \\
\text { Length }(\mathrm{cm})\end{array}$ & $\begin{array}{l}\text { Number of } \\
\text { Male } \\
\text { Inflorescence } \\
\text { /Branch }\end{array}$ & $\begin{array}{l}\text { Ratio of } \\
\text { Female Flower } \\
\text { Clusters to } \\
\text { Mixed } \\
\text { Inflorescence } \\
\text { Number }\end{array}$ & $\begin{array}{l}\text { The Ratio of } \\
\text { the Number of } \\
\text { Female } \\
\text { Flowers to the } \\
\text { Number of } \\
\text { Male } \\
\text { Inflorescences }\end{array}$ & $\begin{array}{l}\text { Ratio of Mixed } \\
\text { Inflorescence } \\
\text { Number to } \\
\text { Male } \\
\text { Inflorescence } \\
\text { Number }\end{array}$ \\
\hline C & 0 & $2.71 \pm 1.62 b$ & $2.11 \pm 0.93 a$ & $16.33 \pm 2.61 \mathrm{a}$ & $8.44 \pm 3.43 b$ & $1.5 \pm 0.40 \mathrm{a}$ & $0.47 \pm 0.27 \mathrm{a}$ & $0.34 \pm 0.15 a$ \\
\hline GA & $100 \mathrm{mg} / \mathrm{L}$ & $2.36 \pm 0.50 \mathrm{~b}$ & $2.14 \pm 0.53 a$ & $12.65 \pm 2.34 \mathrm{~b}$ & $11.14 \pm 2.98 \mathrm{a}$ & $1.14 \pm 0.31 \mathrm{~b}$ & $0.22 \pm 0.06 \mathrm{~b}$ & $0.21 \pm 0.07 a$ \\
\hline $\mathrm{PP}_{333}$ & $1000 \mathrm{mg} / \mathrm{L}$ & $3.70 \pm 1.42 \mathrm{a}$ & $2.40 \pm 0.84 a$ & $17.40 \pm 2.94 a$ & $8.80 \pm 1.87 \mathrm{~b}$ & $1.58 \pm 0.34 \mathrm{a}$ & $0.46 \pm 0.25 a$ & $0.30 \pm 0.15 a$ \\
\hline
\end{tabular}

Different lowercase letters ( $a$ and $b$ ) in each column indicate significantly differences between samples at $5 \%$ level. 


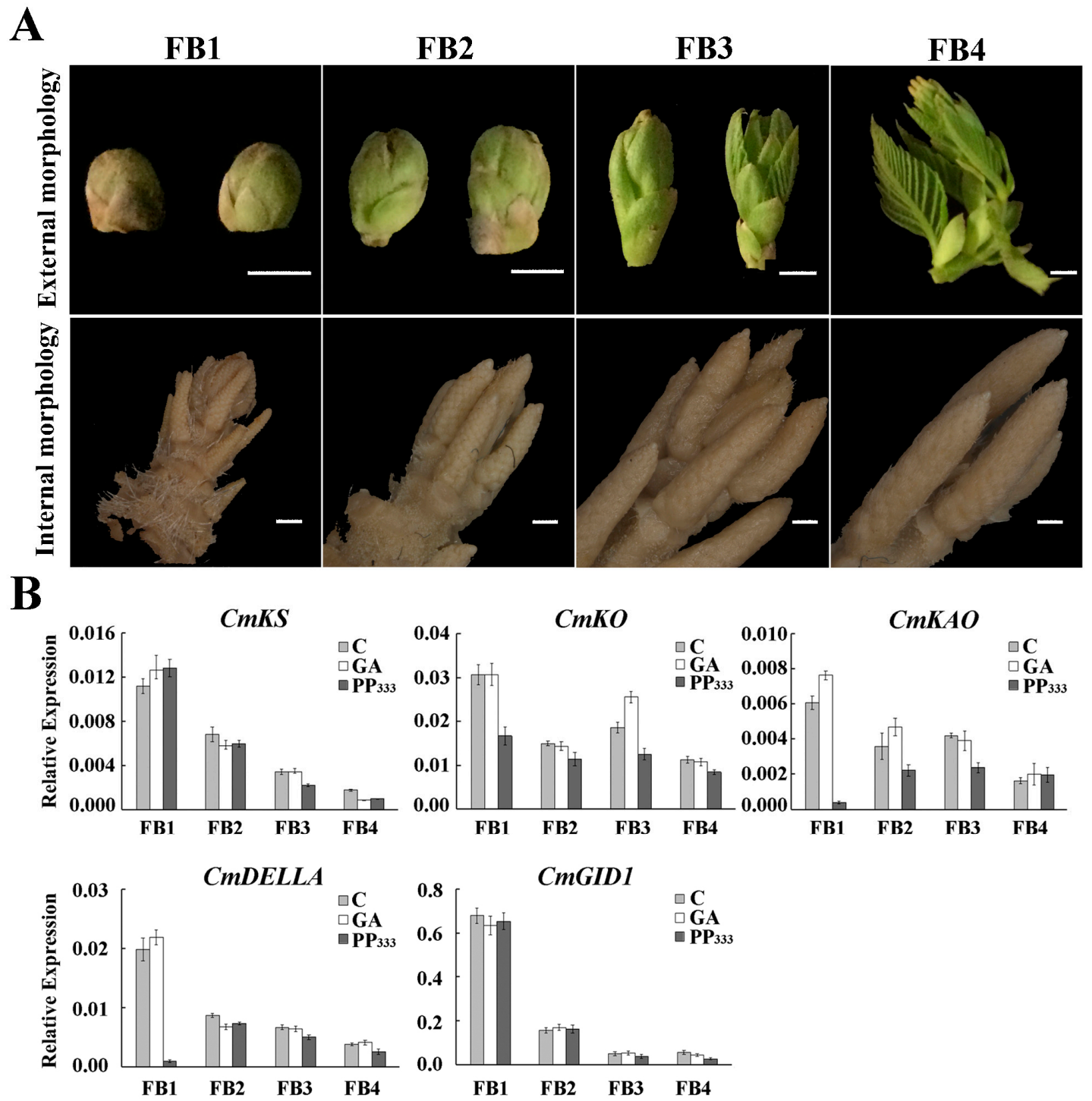

Figure 1. (A) Internal and external forms of floral buds at four time periods. The external morphology was imaged using an ordinary camera with a scale of $5 \mathrm{~mm}$. The internal morphology was photographed using a stereomicroscope with a scale of $500 \mathrm{~m}$. The Floral Bud 1 (FB1)-FB4 samples (corresponding to the four different time periods) were collected on 4, 10, 17, and 24 April 2017, respectively. (B) Expression profiles of key genes in gibberellin (GA) synthesis and signaling pathways at different floral bud stages under the three treatments. The ent-kaurene synthase (KS), ent-kaurene oxidase $(K O)$, and ent-kaurenoic acid oxidase $(K A O)$ genes are involved in the GA synthesis pathway, and the DELLA and GA-insensitive drawf1 (GID1) genes are involved in the GA signaling pathway. The gray column represents the blank control, the white column represents the GA treatment, and the black column represents the $\mathrm{PP}_{333}$ treatment.

Some genes play important roles in flower development $[15,40,41]$, and six of these (SPL9, SPL16, SOC1, AP1, FUL, and LEY) were selected. The gene expression levels in floral buds at different developmental stages were determined by fluorescence quantitative RT-PCR analysis, and the expression trends of the six genes were different. Specifically, SPL9, SPL16, and AP1 showed an upward trend during floral bud development, and the SOC1, FUL, and LEY genes showed a downward trend. After GA treatment, the expression levels of SPL9 and SPL16 were significantly decreased, whereas no significant differences in the gene expression levels of AP1, FUL, and LEY were found between the GA-treated and control floral buds (Figure 2). These results suggested that SPL9 and SPL16 might be involved in not only flower development but also the GA signaling pathway in chestnut. 

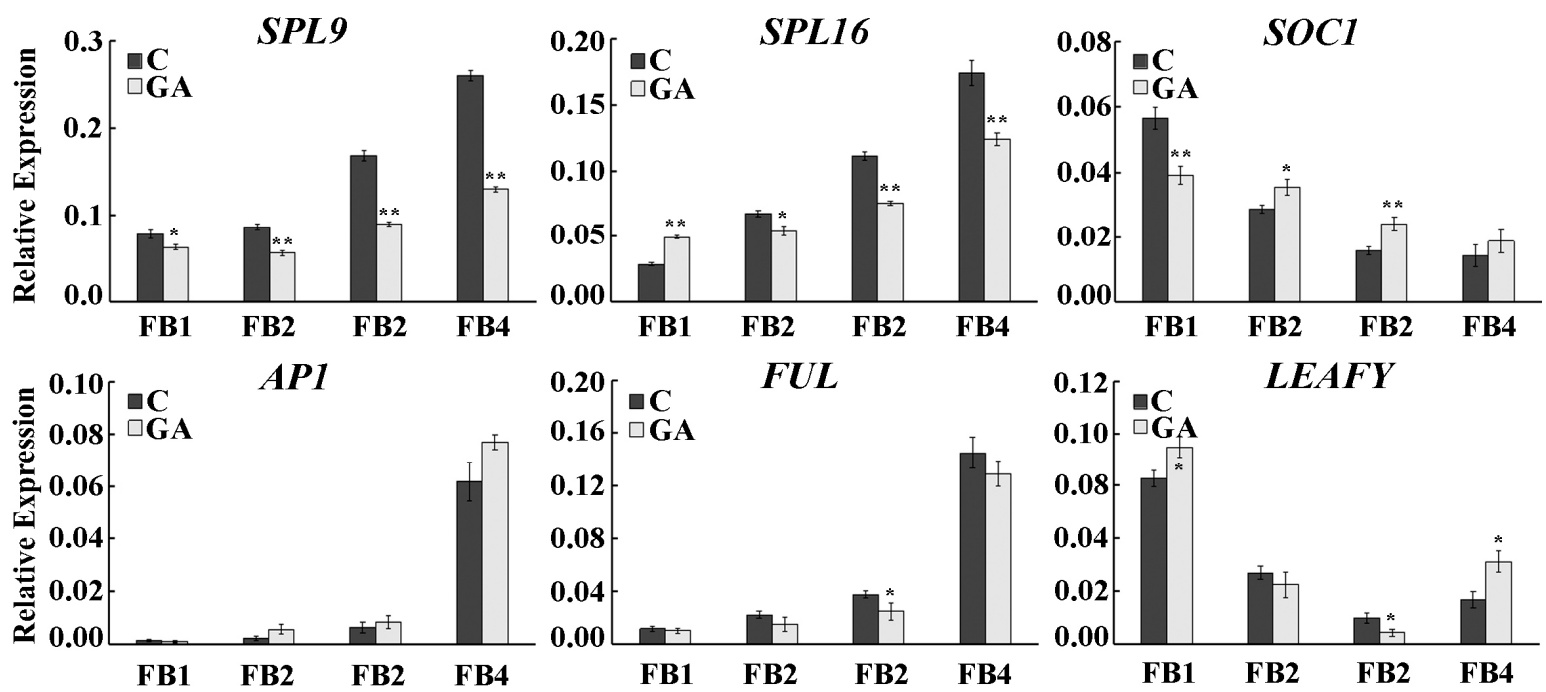

Figure 2. Expression patterns of SPL9, SPL16, SOC1, AP1, FUL, and LEY in floral buds at different stages under GA treatment. The black column represents the blank control, and the gray column represents the GA treatment. Asterisks indicate significant differences according to a Student's $t$-test $\left({ }^{*} p \leq 0.05 ; * * 0.01\right)$.

\subsection{Identification of CmSPL Genes}

To further explore the important role of the SPL genes in flower development, we analyzed the cDNA sequence of the SPL gene family in chestnut and included the deduced protein length, molecular weight, isoelectric point, and aliphatic index. The deduced length of the CmSPL proteins ranged from 151 (CmSPL15) to 1091 (CmSPL14) amino acids, they had a predicted molecular mass of 17.3 (CmSPL15) to 120.6 (CmSPL14) KDa, the pI values ranged from 5.72 (CmSPL7) to 9.39 (CmSPL2), and the Ai varied from 29.74 (CmSPL15) to 84.41 (CmSPL1). In addition, 10 of the 18 genes belonging to the $S P L$ family have a target site for CmmiR156, and two types of complementary regions of CmmiR156 are found in these CmSPLs, most of which are located in the coding region and a few are located in the 3' UTR region of CmSPL (Table 2). These results indicated the diversity in the features of the CmSPLs in C. mollissima.

Table 2. Gene feature and classification of Squamosa promoter-binding protein-like (SPL) in Castanea mollissima.

\begin{tabular}{ccccccc}
\hline Gene Name & CDS (bp) & Peptide (aa) & Mw (Da) & pI & Ai & miR156 Target \\
\hline CmSPL1 & 3000 & 999 & 110899.70 & 5.77 & 84.41 & No \\
CmSPL2 & 582 & 193 & 21864.54 & 9.39 & 51.50 & Yes \\
CmSPL3 & 549 & 182 & 20368.72 & 8.73 & 51.43 & No \\
CmSPL4 & 1314 & 437 & 48311.02 & 7.05 & 57.41 & Yes \\
CmSPL5 & 1722 & 573 & 62793.15 & 6.66 & 57.87 & Yes \\
CmSPL6 & 1623 & 540 & 60015.14 & 6.15 & 68.24 & Yes \\
CmSPL7 & 2358 & 785 & 87807.21 & 5.72 & 76.28 & No \\
CmSPL8 & 1026 & 341 & 37999.46 & 8.98 & 44.75 & No \\
CmSPL9 & 1119 & 372 & 39809.28 & 9.37 & 47.55 & Yes \\
CmSPL10 & 1410 & 469 & 52259.35 & 8.65 & 52.47 & Yes \\
CmSPL11 & 1398 & 465 & 51284.57 & 8.03 & 58.11 & Yes \\
CmSPL12 & 3108 & 1035 & 114576.19 & 7.32 & 84.38 & No \\
CmSPL13 & 1176 & 391 & 42863.75 & 8.80 & 62.58 & Yes \\
CmSPL14 & 3276 & 1091 & 120636.02 & 7.86 & 74.28 & No \\
CmSPL15 & 456 & 151 & 17311.85 & 6.71 & 29.74 & No \\
CmSPL16 & 960 & 319 & 34804.61 & 9.15 & 60.19 & Yes \\
CmSPL17 & 1173 & 390 & 43054.10 & 8.47 & 69.00 & Yes \\
CmSPL18 & 624 & 207 & 23511.61 & 9.32 & 53.24 & No \\
\hline
\end{tabular}




\subsection{Phylogenetic Analysis of SPL Genes}

The SPL gene function has been almost fully clarified in Arabidopsis due to its importance as a model plant. To further study the evolutionary relationship among C. mollissima, Arabidopsis, and $P$. trichocarpa, the sequences of 18 CmSPLs from chestnut, 13 AtSPLs from Arabidopsis, and 28 PtSPLs from $P$. trichocarpa were analyzed through a phylogenetic tree analysis. All 59 SPL genes were divided into eight groups, and seven of the groups (all except IV) contained at least one SPL gene from three species (Figure 3). V includes the smallest SPL gene, which contains less than 210 amino acids, and VII encodes a large set of SPL genes with approximately 1000 amino acids (Figure 3 and Table 2). Therefore, although the construction of the phylogenetic tree was based on the SBP domain, the tree also reflected the evolution and classification of the full-length SPL genes, which also indicated that the SBP domain is a relatively conserved sequence among all SPL genes of different species. In addition, with the exception of CmSPL17 in I, the homologous relationship between other chestnut SPL genes and the poplar SPL gene is closer than that of chestnut genes with Arabidopsis, which indicates that the conservation of the SPL gene family among woody plants is higher than that among woody and herbaceous plants.

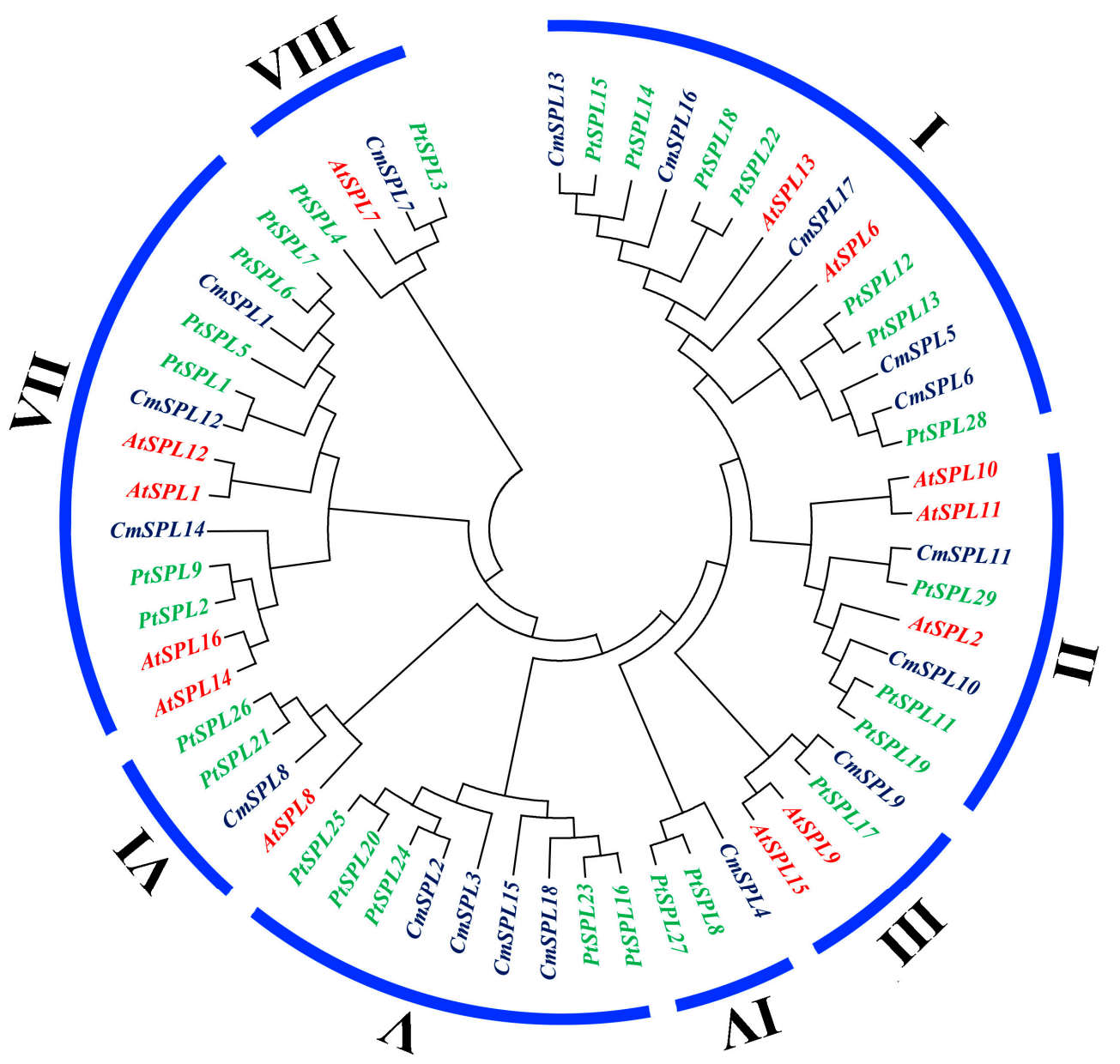

Figure 3. Phylogenetic tree of 59 SPLS in C. mollissima, Arabidopsis thaliana, and Populus trichocarpa. The phylogenetic tree was constructed based on the SBP domain using the neighbor-joining (NJ) method with MEGA 7. The number on the branch indicates the bootstrap value, and the SPL genes in the same species are represented with the same colors: purple, C. mollissima; red, A. thaliana; and green, P. trichocarpa. 


\subsection{Identification of Conserved Motifs in CmSPLs}

The detailed domain structure of CmSPL was analyzed by NCBI database alignment, and the results showed that the SBP domain is the only conserved domain shared by all CmSPLs. As shown in Figure 4A, all SBP domains in CmSPLs also contain two zinc finger structures (Zn-1/2) and a conserved nuclear localization signal (NLS). The Zn-1 motif is a $\mathrm{CCCH}(\mathrm{C} 3 \mathrm{H})$ type in all CmSPL proteins except that the His residue in CmSPL7 is substituted with a Cys residue. Unlike $\mathrm{Zn}-1$, the characteristic sequence of $\mathrm{Zn}-2$ (C2HC) is highly conserved in all CmSPLs, which partially overlap NLS.

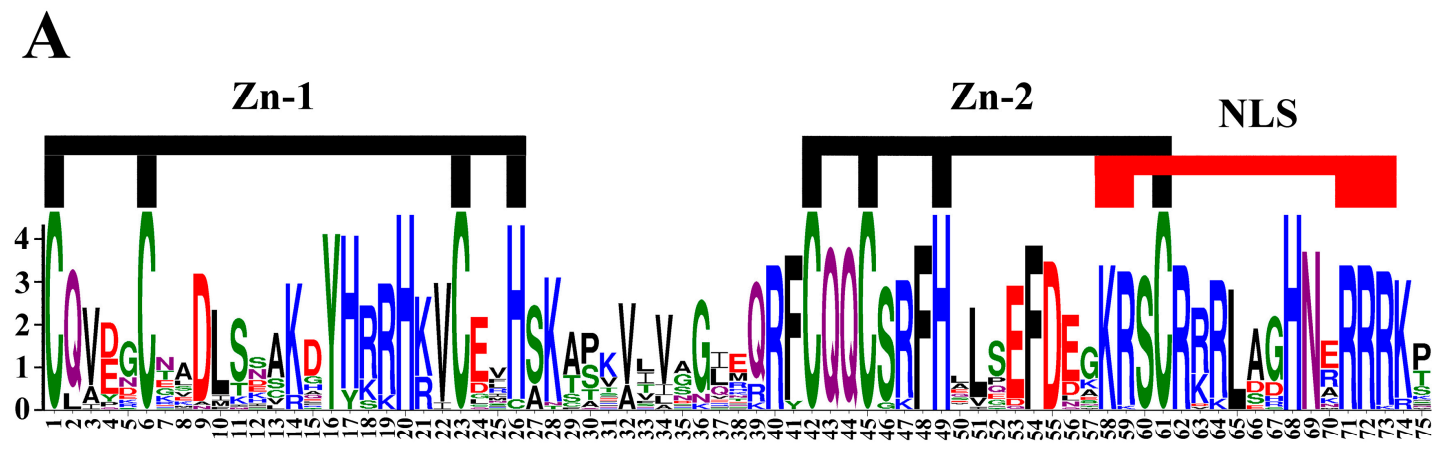

B

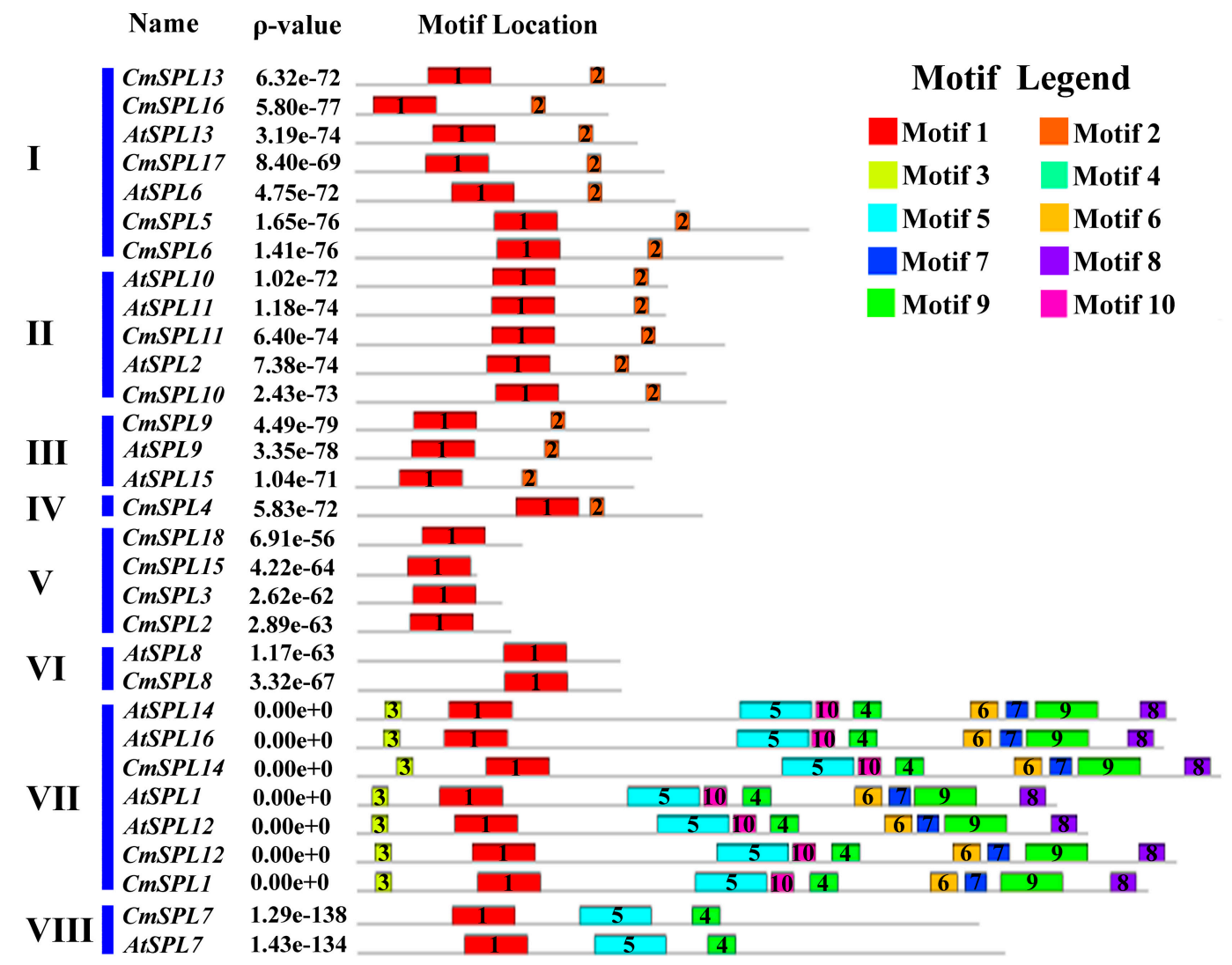

Figure 4. Conserved motif analysis. (A) Sequence logo of the SBP domain of CmSPLs. The overall height of each stack represents the degree of conservation at this position, whereas the height of the letters within each stack indicates the relative frequency of the corresponding amino acids. (B) Distribution of conserved motifs in CmSPLs. The motifs represented with boxes were identified using the MEME online tool. The numbers in boxes 1-10 represents motifs $1-10$, respectively. The position and length of each colored box represents the actual motif size. 
In addition to the SBP domain, other conserved domains also play an important role in protein function. For example, ANK domains involved in protein-protein interactions were relatively conserved in most of the investigated proteins. An analysis of 10 conserved domains in 18 CmSPLs was performed using the MEME web server (Figure 4B). Consistent with the phylogenetic tree analysis, we also divided the structures of these 31 SPL proteins into eight groups. Most of the domains were relatively conserved between Arabidopsis and chestnut and were also relatively conserved in poplar trees. The number of motif(s) in each CmSPL varied from 1 to 9, and most CmSPLs within the same group shared similar motif profiles (Figure 4B). Among these motifs, motif 1 is the SBP domain, which exists in all CmSPLs analyzed, and motif 2 consists of a sequence containing a region complementary to miR156.

\subsection{Expression Profiles of the SPL Genes and miR156 in Organs of C. mollissima}

Both the evolutionary relationship and gene structure analyses showed the conservation and diversity of SPL genes. We also aimed to explore the role of these SPL genes in the development of Chinese chestnut flowers and thus analyzed the expression patterns of 18 genes in different organ samples (female flowers, male flowers, leaves, ovary, stigma, and stamen) by qRT-PCR. In general, the CmSPL genes were classified into two types based on their expression profiles (Figure 5B,C). A minority of the CmSPL genes, namely, CmSPL1, CmSPL12, and CmSPL14, showed relatively high expression in all the examined organs (Figure 5B). All of these genes are devoid of miR156 complementary regions and are therefore referred to as the CmmiR156-nontargeted CmSPL genes. The remaining CmSPL genes, most of which are CmSPL genes with complementary regions of CmmiR156, are therefore known as CmmiR156-targeted CmSPL genes, showing more differentiated expression patterns in different organs (Figure 5). This difference implies that CmmiR156-targeted and -nontargeted CmSPL genes play distinct roles in flower development in C. mollissima. It is worth noting that similar expression patterns were observed in genes belonging to the same group, such as CmSPL5/13/17 in group I, CmSPL1/12/14 in group VII, and CmSPL2/15 in group V (Figure 5). This suggests that the same group of CmSPLs plays a similar function in flower development due to their identical motifs. Furthermore, we also studied CmmiR156 transcript levels in different organs of C. mollissima by qRT-PCR. According to its expression pattern, CmmiR156 was mainly expressed in the male floral cluster and stamen, and the level of CmmiR156 in these organs was approximately twofold higher than that found in the female flower, which presented the third highest expression of this gene (Figure $5 \mathrm{~A})$. In contrast, most of the CmmiR156-targeted CmSPL genes showed higher expression in male flowers than in male floral clusters and stamen.

\subsection{Expression Pattern of miR156 and Its Target Genes in Floral Buds at Different Stages under GA Treatment}

GA is an important hormone in plant growth and development and plays an important role in floral transition. In our study, CmmiR156 was downregulated in the development of floral buds and increased significantly after GA treatment (Figure 6A). Thus, the expression patterns of $18 \mathrm{CmSPL}$ genes during floral bud development were also analyzed. Most of the CmmiR156-targeted CmSPL genes, particularly CmSPL6, CmSPL9, CmSPL10, CmSPL13, and CmSPL16, were substantially upregulated during floral bud development (Figure 6B). In addition, CmSPL6, CmSPL9, and CmSPL16 expression was significantly decreased during GA treatment and showed the opposite expression patterns from that of CmmiR156. In addition, the CmmiR156-nontargeted CmSPL genes exhibited a constitutive expression pattern during floral bud development, and the expression level did not significantly differ under GA treatment (Figure 6C). These results demonstrate that CmmiR156-targeted and -nontargeted CmSPLs play an important role in the floral bud development of $C$. mollissima, and there is a functional difference between them. 


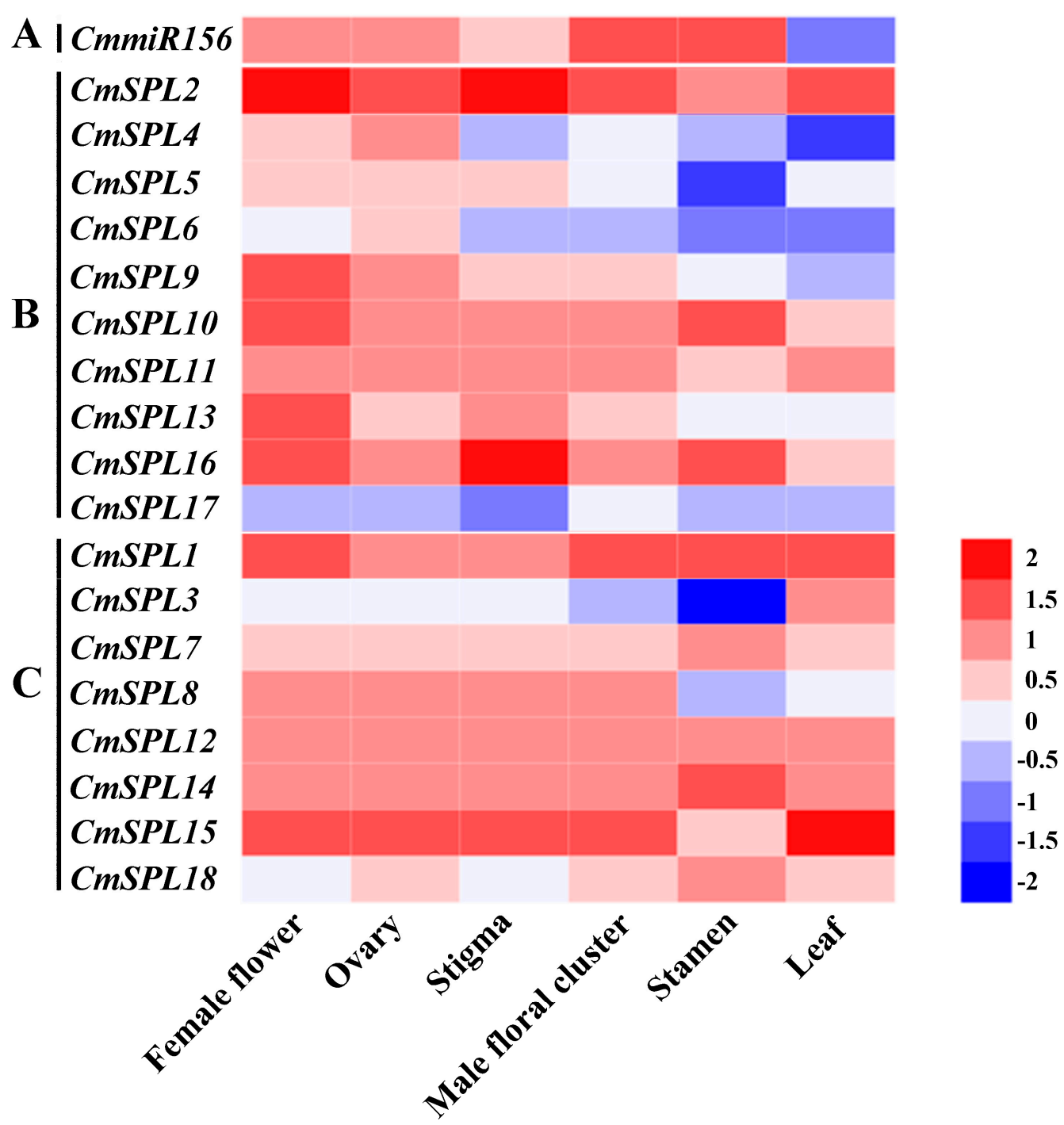

Figure 5. Expression profiles of the Chinese chestnut CmSPL genes in female flower, male floral cluster, leaf, ovary, stigma, and stamen. The heat map was generated based on the mean values from the qRT-PCR data obtained from the different samples. The red and blue colors represent higher and lower expression, respectively.

2.7. Validation of CmmiR156-Targeted CmSPLs Cleavage Sites by RNA Ligase-Mediated Rapid Amplification of the $5^{\prime}$ CDNA Ends (RLM-RACE)

In our study, $10 \mathrm{CmSPL}$ genes with complementary regions for CmmiR156 were identified. Most of the CRs were highly paired with only one base mismatch located at the eighth base (Figure 7A). The CmSPL9 and CmSPL16 target genes were selected for section analysis using the RLM-RACE technique. Cloning and sequencing of the PCR amplicons of remnant mRNAs enabled the determination of the nucleotide position in which a slicing event occurred. CmmiR156 sliced its CmSPL9 and CmSPL6 target genes at different sites with different efficiencies. Specifically, the CmSPL9 and CmSPL16 slicing events occurred at the 12th/10th nucleotide in the CR, and the efficiencies of these splicing reactions were $10 / 10$ and $8 / 10$, respectively (Figure $7 \mathrm{~B}$ ). 
A

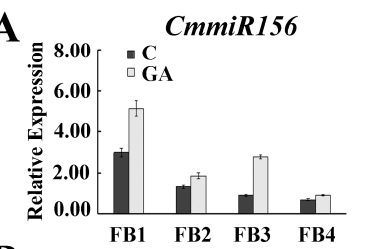

B
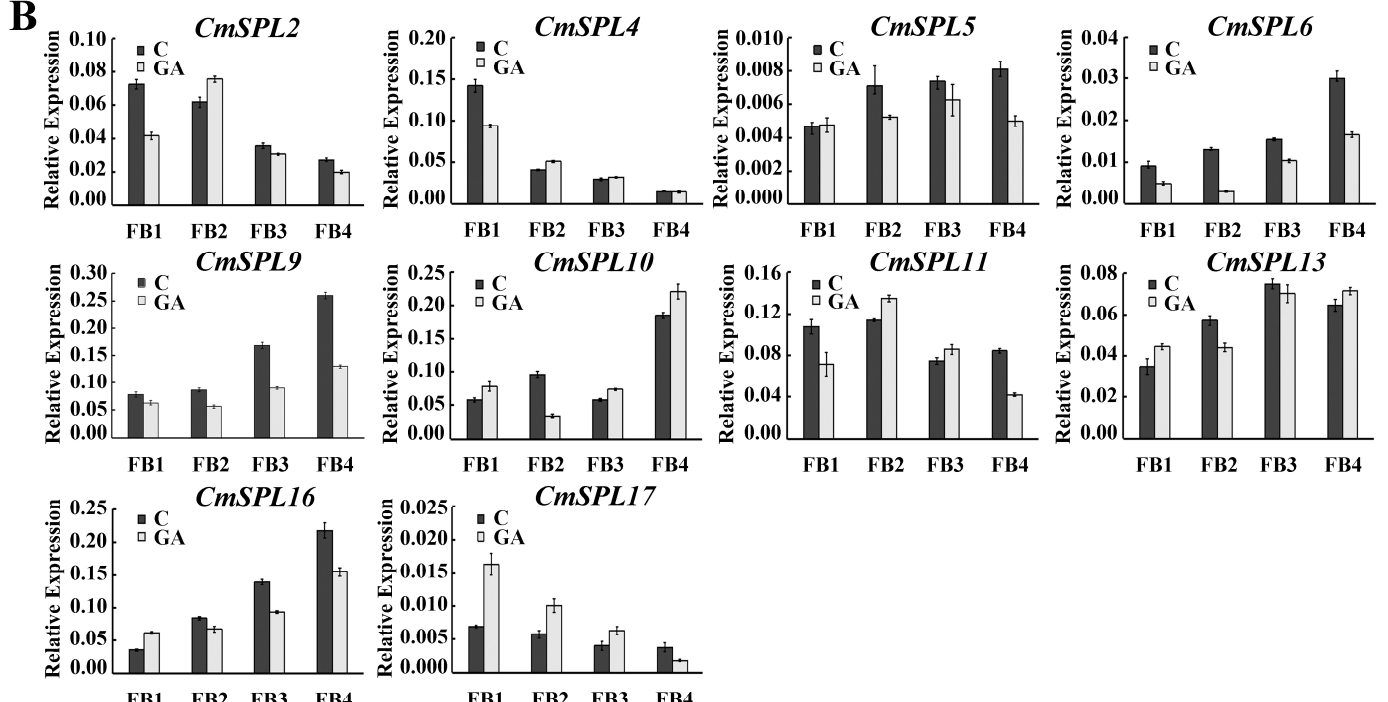

C
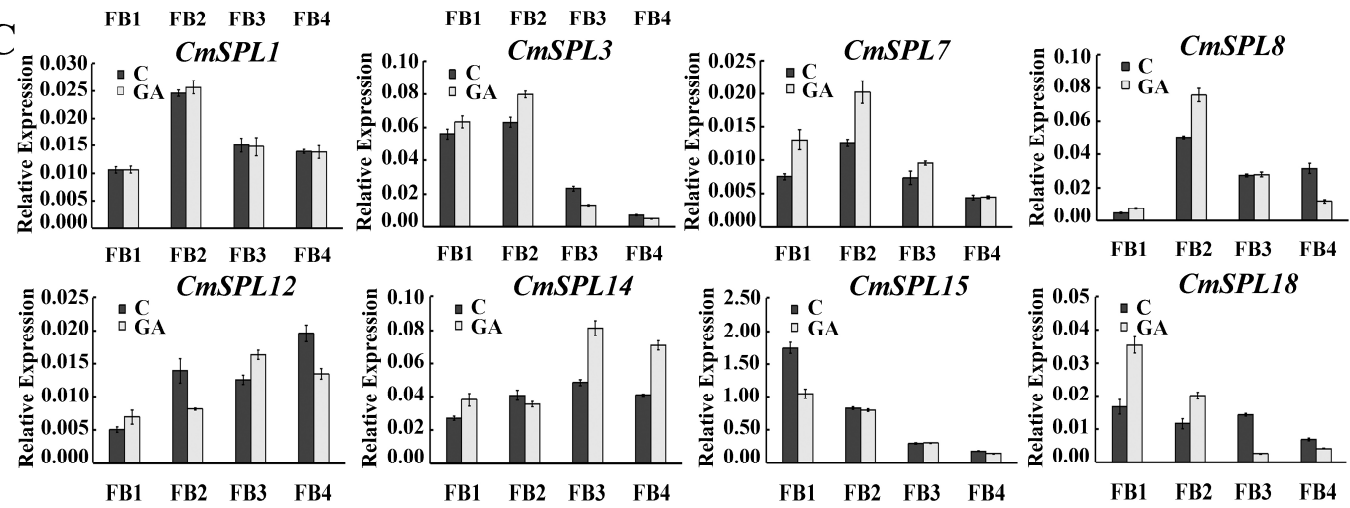

Figure 6. Expression profiles of mature CmmiR156 and CmSPLs in floral buds of C. mollissima at different stages under GA treatment. (A) Expression patterns of CmmiR156. (B) Expression patterns of CmmiR156-targeted CmSPLs. (C) Expression patterns of CmmiR156-nontargeted CmSPLs. Floral Bud 1 (FB1)-FB4 represent the floral buds at four different periods (4, 10, 17, and 24 April 2017, respectively).

A

CmmiR156 3'-ACACGAGUGAGAGAAGACAGU-5'

CMSPL2 5'-CATGCT CT CT CT CTT CT GTCA-3,

CmSPL4 5'-TGTGCT CT CT CT CTT CT GTCA-3'

CmSPL5 5'-TGTGCT CTCT CT CTTCT GTCA-3'

CmSPLG 5'-TGTGCT CT CT CT CTT CT GTCA-3'

CmSPL9 5'-TGTGCT CT CT CT CTT CT GTCA-3,

CmSPL10 5'-CGTGCT CT CT CT CTT CT GTCA-3'

CmSPL11 5'-CGTGCT CT CT CT CTT CT GTCA-3'

CmSPL13 5'-TGTGCT CT CT CT CTT CT GTCA-3'

CmSPL16 5'-TGTGCT CT CT CT CTT CT GTCA-3'

CmSPL17 5'-T TTGCT CT CT AT CTT CT GTCA-3'

\section{B}
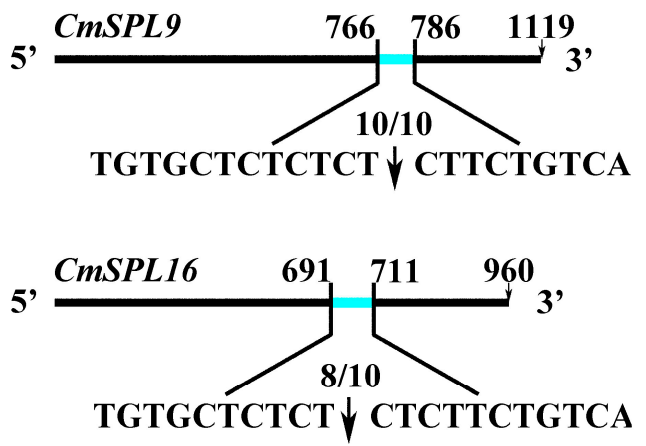

Figure 7. Identification of CmmiR156-guided cleavage products of target genes. (A) Sequence of the miR156 complementary region in CmSPL genes. (B) Sites for the cleavage of CmSPL9 and CmSPL16 by CmmiR156. The black arrow indicates the cutting site. 


\section{Discussion}

SPLS are plant-specific transcription factors that contain a highly conserved SBP domain and have a large family in plants. Due to the important function of SPL genes in plant development, more and more species of SPLs have been identified. Chestnut is an important ecological and economic crop, and its SPL genes have not been systematically studied. Because of the different proportions of male and female flowers in chestnut and the important function of SPL genes in floral development, we believe that the identification and analysis of chestnut SPL genes is of great significance. In this study, we identified 18 SPL genes in the C. mollissima genome, and expression analysis showed that most of them had relatively high expression in floral organs (Figure 5). Compared with Arabidopsis thaliana [17], Vitis vinifera [42], P. hybrida [21], P. trichocarpa [18], and B. luminifera [19], the number of chestnut SPL genes is similar to that of Arabidopsis (16), B. luminifera (18) and $V$. vinifera (18), but notably lower that of P. trichocarpa (28), and P. hybrida (21). This finding means that the SPL genes of different plants evolve in a species-specific manner, which may be affected by different genetic repeat events.

According to the phylogenetic tree analysis, we divided $18 \mathrm{CmSPL}$ genes into eight groups (I-VIII) (Figure 3). The tight integration of the CmSPL genes with the AtSPL and PtSPL genes suggests that the first origins of these SPL genes may be identical and may have a common ancestor. By conservative motif analysis, it was found that all CmSPL genes from the same phylogenetic group had the same motif (Figure 4B), indicating that the genes of the same phylogenetic group may have similar functions in C. mollissima. To investigate the potential role of CmSPLs in the floral development of chestnut, the expression profiles of CmSPL genes in six different organs of chestnut were analyzed. In addition, due to the correlation between CmSPLs and CmmiR156, we also analyzed the expression profile of CmmiR156. The expression pattern of the CmSPL genes in different organs of chestnut are shown in Figure 5. Some CmSPLs (CmSPL1, CmSPL12, and CmSPL14) exhibited a constitutive expression pattern in the examined organs, and the remaining genes exhibited development- and organ-dependent expression patterns. Notably, the constitutive expression patterns were typically observed in the CmmiR156-nontargeted CmSPL genes, whereas more than half of the CmmiR156-targeted CmSPLs tended to exhibit different expression patterns. The miR156-targeted and -nontargeted SPL genes also have similar expression differences in P. trichocarpa, B. luminifera, B. napus, and P. hybrida [18-21]. This finding suggests that miR156-targeted and -nontargeted SPLS undergo different evolutionary patterns of differentiation expression, suggesting that they play distinct roles in the development and growth of plants.

The DELLA protein has been found to interact with the SPL protein as a central transcriptional repressor of the GA response and to inhibit SPL protein activity. The physical interaction between SPL and DELLA is considered to be an integrator of age and GA-related pathways at flowering [43]. This experiment revealed no significant difference in the level of DELLA expression under GA treatment compared with the control treatment, which might indicate that DELLA is not sensitive to GA. The first spraying treatment with $\mathrm{PP}_{333}$ significantly reduced the expression of DELLA (Figure 1B). This protein is also involved in the transmission of various plant hormones and environmental signals, such as abscisic acid (ABA) [44], jasmonic acid (JA) [45], sugar signal [46], and light signal $[47,48]$. The reduced DELLA expression level might be due to the fact that the tree just started to come into contact with $\mathrm{PP}_{333}$, resulting in an imbalance in other internal hormones, which in turn affects the expression level of DELLA protein. The extensive interaction between DELLA protein and miR156-targeted SPLs has been demonstrated in several species by yeast two-hybrid assays. For example, in B. luminifera, BIRGA can interact with BISPL1, BISPL6, BISPL8, BISPL13, and BISPL18, and BIRGL can interact with BISPL1, BISPL8, BISPL13, BISPL16, and BISPL18 [19]. In this study, we found that the expression patterns of CmSPLs and CmmiR156 were also affected by GA treatment. During floral bud development, GA treatment significantly increased the expression level of CmmiR156 and decreased the expression of the target gene CmSPL6/CmSPL9/CmSPL16. Some nontarget genes, such as CmSPL7/CmSPL14/CmSPL18, showed increased expression levels during some stages of floral bud development. The similar expression pattern was also found in Phyllostachys edulis and upland 
cotton $[49,50]$, suggesting that the expression of the SPL genes may be regulated by GA and indicates that GA can indirectly affect the expression of SPL genes by regulating miR156 or directly regulate the expression level of SPLs by affecting the interaction between DELLA and SPL proteins.

\section{Materials and Methods}

\subsection{Plant Materials}

The Chinese chestnut cultivar "Yanshanhongli" was used in this study. Samples of different organs, including mixed floral bud, female flower, stigma, ovary, staminate catkin, male floral cluster, stamen, and leaf, were collected from 18-year-old Yanshanhongli plants in the Chestnut Experiment Station in the Huairou District of Beijing, China. The stigma and ovary samples were collected from unpollinated female flowers by removing the catkins and isolating the female flowers via bagging. All samples were cleaned after collection and immediately frozen in liquid nitrogen and stored at $-80{ }^{\circ} \mathrm{C}$ until RNA extraction.

\subsection{Exogenous Hormone Application}

A stock solution containing $1 \mathrm{~g}$ of $\mathrm{GA}_{3}$ and $10 \mathrm{~g}$ of $\mathrm{PP}_{333}$ dissolved in $50 \mathrm{~mL}$ of $95 \%$ alcohol was diluted with distilled water to a final volume of $10 \mathrm{~L}$. The final concentrations of $\mathrm{GA}_{3}$ and $\mathrm{PP}_{333}$ were $100 \mathrm{mg} / \mathrm{L}$ and $1000 \mathrm{mg} / \mathrm{L}$, respectively. The control treatment involved the spraying of distilled water containing an equal amount of ethanol. Ten chestnut trees of similar growth were used for each treatment. The first spraying was performed prior to floral bud sprouting on 20 March 2017, and the trees were then sprayed three more times at 1-week intervals. In the middle of June, 40 branches at different positions were randomly selected from 10 chestnut trees in each treatment, and the total number and length of catkins of mixed inflorescences, male inflorescence, and female flowers in each sub-branch were investigated. SPSS 22.0 software was used for statistical analysis.

\subsection{Identification of CmSPL Genes}

Chinese chestnut gene and protein sequences were obtained from the Chinese chestnut genome project (https:/ / www.ncbi.nlm.nih.gov/bioproject/527178), and two methods were used to identify SPL genes in Chinese chestnut. First, the hidden Markov model (HMM) profile of the SBP domain (pfam03110) was obtained from the Pfam website (http:/ / pfam.xfam.org/) [51] and was employed as the query for the identification of all possible SPL genes in Chinese chestnut. Additionally, the Arabidopsis information resource database (http://www.arabidopsis.org/) was used to search the amino acid sequence of AtSPLs, and the sequence of PtSPLs was obtained from previous studies [18]. Then, the AtSPL and PtSPL sequences were used as queries for BLASTP searches against the Chinese chestnut genome database. All of the candidate SPL genes identified using the two methods were downloaded from the Chinese chestnut genome website. The reliability of these candidate sequences was verified using the Pfam (http://Pfam.sanger.ac.uk/) and NCBI databases (http:/ /www.ncbi.nlm. nih.gov/), and the sequences lacking SBP domains were rejected.

\subsection{Bioinformatic Analyses of CmSPL Genes}

The amino acid sequence length, molecular weight, and isoelectric point of the candidate protein were calculated using the ExPASy website tool (http://web.expasy.org/protparam/). Conservative motifs were identified using the online tool MEME (http://meme-suite.org/tools/meme) with parameter settings referenced to previous studies [18], using the psRNATarget tool (http:/ / plantgrn. noble.org/v1_psRNATarget/) to predict miiR156-targeted SPL genes.

\subsection{Phylogenetic Analysis}

The SBP domain sequences were obtained from SPL protein sequence alignment analysis using NCBI. A phylogenetic analysis was performed with reference to the MEGA 7.0 tool used by Kumar et al. [52]. 


\subsection{RNA Isolation}

The total RNA from tissues or organs of C. mollissima was extracted using the Plant RNA Kit (OMEGA, Norcross, GA, USA) according to the manufacturer's instructions. The quality and quantity of total RNA were evaluated by agarose gel electrophoresis and using a Nanodrop One spectrophotometer (Thermo Scientific, Madison, NY, USA), respectively, and the elimination of genomic DNA through treatment with RapidOut DNA Removal Kit (Thermo Scientific, Vilnius, Lithuania).

\subsection{Expression Analysis of CmSPL Genes}

The cDNA was synthesized using M-MLV reverse transcriptase (Takara, Dalian, China). qRT-PCR analysis was performed by the Light Cycler96 Real Time PCR System (Roche Diagnostics GmbH, Mannheim, Germany) with SYBR Green (Takara, Dalian, China). The gene-specific primers were designed using Beacon designer software and are listed in Table A1. Each reaction system and procedure of qRT-PCR was based on the study of Lu et al. [53]. All qRT-PCR experiments were performed in three biological replicates. The relative expression levels were calculated using the $2-\Delta C \mathrm{t}$ method and CmActin was employed as the reference gene.

\subsection{Expression Analysis of CmmiR156}

Briefly, $2 \mu \mathrm{g}$ of total RNA treated with DNase was used for first-strand cDNA synthesis using the TransScript $^{\circledR}$ miRNA First-Strand cDNA Synthesis SuperMix Kit (TransGen Biotech, Beijing, China). In the qRT-PCR analysis of miR156, U6 was used as the reference gene. The program parameters were set as mentioned above, and the primers are listed in Table A1.

\subsection{RLM-RACE}

To identify the CmmiR156 cleavage sites of the CmSPL transcripts, a modified 5'RLM-RACE program was used with the First Choice RLM-RACE kit (Invitrogen, Vilnius, Lithuania) following the method used by Li et al. [19]. Specific primers were designed based on predicted cleavage sites (Table A1), then the 5' RACE PCR product was gel-purified and cloned into the pMD-19 T vector (Takara, Dalian, China), and 10 clones were randomly selected and sequenced.

\section{Conclusions}

In this study, we identified 18 SPL genes in the C. mollissima genome and analyzed their evolutionary relationships, gene structures, expression patterns, and potential functions. The development of male and female flowers in chestnut and the expression of some SPL genes were affected by GA treatment. The present work provides an important foundation for the future elucidation of the biological functions of CmSPL genes.

Author Contributions: Conceptualization, G.C., L.Q., and Y.X.; methodology, G.C. and J.L.; software, G.C. and Y.L.; validation, L.Q. and Y.X.; formal analysis, Q.Z., Y.G., and K.F.; investigation, G.C., J.L., and Y.L.; resources, L.Q.; writing—original draft preparation, G.C., J.L., L.Q., and Y.X.; writing-review and editing, G.C., Q.C., and Y.X.; visualization, G.C., J.L., and K.F.; supervision, Y.X.; project administration, L.Q.; funding acquisition, L.Q. and Y.X.

Funding: This work was supported by the National Key Research \& Development Program of China (2018YFD1000605), the National Natural Science Foundation of China (Grant nos. 31370679 and 31270719), and the Project of Construction of Innovative Teams and Teacher Career Development for Universities and Colleges under Beijing Municipality (IDHT20180509).

Conflicts of Interest: The authors declare that the research was conducted in the absence of any commercial or financial relationships that could be construed as a potential conflict of interests. 


\section{Appendix A}

Table A1. Primers used for this study.

\begin{tabular}{|c|c|}
\hline & Primer Set \\
\hline & Forward and Reverse primer $\left(5^{\prime}-3^{\prime}\right)$ \\
\hline & For qRT-PCR analysis \\
\hline \multirow{2}{*}{ miRNA RT Primer } & GATCGCCCTTCTACGTCGTATCGTCATCTGA \\
\hline & CCGTTATCGCTGCACGTTTTTTTTTTTTTTTTTTTT \\
\hline CmmiR156-F & TGCACTAGCGTGTGACAGAAGA \\
\hline CmmiR156-R & GATCGCCCTTCTACGTCGTAT \\
\hline U6-F & GATAAAATTGGAACGATACAG \\
\hline U6-R & ATTTGGACCATTTCTCGATTT \\
\hline CmActin-F & ATTCACGAGACCACCTACA \\
\hline CmActin-R & TGCCACAACCTTAATCTTCA \\
\hline CmSPL1-F & CAGTCAAGTCCACCTCAA \\
\hline CmSPL1-R & GCTCTCAATGTCAGTAGGA \\
\hline CmSPL2-F & CATACCATAGGAGGCACAA \\
\hline CmSPL2-R & TCCGTCGCTCATTATGTC \\
\hline CmSPL3-F & TGTAGATGATGACTTGGATGA \\
\hline CmSPL3-R & TTCTCTGCCTGACAACAT \\
\hline CmSPL4-F & CAATGGAGGAACTAGGAGATG \\
\hline CmSPL4-R & GACAATAATCCGAATGCTGAG \\
\hline CmSPL5-F & TCTTCAAGCCATTCATCTG \\
\hline CmSPL5-R & CCAAGGTGATTCTCTTCTG \\
\hline CmSPL6-F & CTGAAGACTATGCTGTTACTG \\
\hline CmSPL6-R & TGACCGACACTATGATGG \\
\hline CmSPL7-F & GAACGCCACAACAATAGA \\
\hline CmSPL7-R & TCAGACTCCAAGAATGCT \\
\hline CmSPL8-F & ATGCTGGACTACGAATGG \\
\hline CmSPL8-R & GATGATGATGTTGATGATGATGA \\
\hline CmSPL9-F & ТССТССАТСТААССТАТАТСТG \\
\hline CmSPL9-R & CTTCCGTATTCATCAAGTCTT \\
\hline CmSPL10-F & ACACCACGCTGCCAAGTT \\
\hline CmSPL10-R & GGAACCTGCTACATTGCTGACA \\
\hline CmSPL11-F & TACACCTCAAGTCCTTAGTCA \\
\hline CmSPL11-R & GCTTCACTGCTTCGGTTA \\
\hline CmSPL12-F & TTCTTCACAGTCACCATCT \\
\hline CmSPL12-R & GCTCTCAATGTCAGTAGGA \\
\hline CmSPL13-F & CTAACCAGCAGCAACAATTACAG \\
\hline CmSPL13-R & AGACAGGAGCCTCAAGAGATAA \\
\hline CmSPL14-F & GCAAGAAGTAGTAGCAGTTAC \\
\hline CmSPL14-R & GGAGAAGACGAAGGAGAC \\
\hline CmSPL15-F & TATCACCGCCGCCACAAG \\
\hline CmSPL15-R & TTCCGTCGCCTCTCATTATGTC \\
\hline CmSPL16-F & TTTATGCGACAATTACAAAGGA \\
\hline CmSPL16-R & GTTTAACCCATTAGAGAACACTT \\
\hline CmSPL17-F & TCTATCTTCTGTCATCACСТC \\
\hline CmSPL17-R & TCATTGGCATCAGGAACA \\
\hline CmSPL18-F & CACAAGCGTCACAAGGTT \\
\hline CmSPL18-R & TCTCTGCCTGAAGGTCTG \\
\hline \multicolumn{2}{|r|}{ For modified 5' RLM-RACE } \\
\hline CmSPL9-outer-R & GGGGAGGTGTCATAAGCCCTGGAGT \\
\hline CmSPL9-inter-R & CCCTGGAGTGCTCAAGTCCCATGTA \\
\hline CmSPL16-outer-R & ACAAGAAGGAAAGTGTTTGGTTAGG \\
\hline CmSPL16-inter-R & TGACCCATCACTATCATGAGGCCCA \\
\hline
\end{tabular}




\section{References}

1. Zhao, Z.Y.; Liu, K.Y. Effect of chemical thinning catkins on Chinese chestnut yield and quality. Acta Hortic. 2009, 844, 457-460. [CrossRef]

2. Guo, X.P.; Li, X.L.; Duan, X.W.; Shen, Y.Y.; Xing, Y.; Cao, Q.Q.; Qin, L. Characterization of sck1, a novel Castanea mollissima mutant with the extreme short catkins and decreased gibberellin. PLoS ONE 2012, 7, e43181. [CrossRef]

3. Tanurdzic, M.; Banks, J.A. Sex-determining mechanisms in land plants. Plant Cell 2004, 16, S61-S71. [CrossRef] [PubMed]

4. Chandler, J.W. The Hormonal Regulation of Flower Development. J. Plant Growth Regul. 2011, 30, $242-254$. [CrossRef]

5. Song, S.; Qi, T.; Huang, H.; Xie, D. Regulation of stamen development by coordinated actions of jasmonate, auxin, and gibberellin in Arabidopsis. Mol. Plant 2013, 6, 1065-1073. [CrossRef] [PubMed]

6. Plackett, A.R.; Ferguson, A.C.; Powers, S.J.; Wanchoo-Kohli, A.; Phillips, A.L.; Wilson, Z.A.; Hedden, P.; Thomas, S.G. DELLA activity is required for successful pollen development in the Columbia eco type of Arabidopsis. New Phytol. 2014, 201, 825-836. [CrossRef] [PubMed]

7. Cheng, Y.F.; Zhao, Y.D. A Role for Auxin in Flower Development. J. Integr. Plant Biol. 2007, 49, 99-104. [CrossRef]

8. Chen, M.S.; Pan, B.Z.; Wang, G.J.; Ni, J.; Niu, L.; Xu, Z.F. Analysis of the transcriptional responses in inflorescence buds of Jatropha curcas exposed to cytokinin treatment. BMC Plant Biol. 2014, 14, 318. [CrossRef] [PubMed]

9. Pan, B.Z.; Xu, Z.F. Benzyladenine Treatment Significantly Increases the Seed Yield of the Biofuel Plant Jatropha curcas. J. Plant Growth Regul. 2011, 30, 166-174. [CrossRef]

10. Fan, X.M.; Yuan, D.Y.; Tian, X.M.; Zhu, Z.J.; Liu, M.L.; Cao, H.P. Comprehensive Transcriptome Analysis of Phytohormone Biosynthesis and Signaling Genes in the Flowers of Chinese Chinquapin (Castanea henryi). J. Agric. Food Chem. 2017, 65, 10332-10349. [CrossRef]

11. Jin, J.P.; Tian, F.; Yang, D.C.; Meng, Y.Q.; Kong, L.; Luo, J.; Gao, G. PlantTFDB 4.0: Toward a central hub for transcription factors and regulatory interactions in plants. Nucleic Acids Res. 2017, 45, D1040-D1045. [CrossRef] [PubMed]

12. Guan, X.; Pang, M.; Nah, G.; Shi, X.; Ye, W.; Stelly, D.M.; Chen, Z.J. miR828 and miR858 regulate homoeologous MYB2 gene functions in Arabidopsis trichome and cotton fibre development. Nat. Commun. 2014, 5, 3050. [CrossRef]

13. Fang, Y.; Xie, K.; Xiong, L. Conserved miR164-targeted NAC genes negatively regulate drought resistance in rice. J. Exp. Bot. 2014, 65, 2119-2135. [CrossRef] [PubMed]

14. Huang, J.; Li, Z.Y.; Zhao, D.Y. Deregulation of the OsmiR160 target gene OsARF18 causes growth and developmental defects with an alteration of auxin signaling in rice. Sci. Rep. 2016, 6, 29938. [CrossRef]

15. Tian, J.; Zhao, X.Y.; Xie, L.S.; Quan, J.Y.; Yao, L.H.; Wang, G.D.; Zheng, Y.Q.; Liu, X.M. Research advances and molecular mechanism on SPL transcription factors in regulating plant flower development. J. Nanjing For. Univ. (Nat. Sci. Ed.) 2018, 42, 159-166. [CrossRef]

16. Li, X.; Zhang, H.; Ai, Q.; Liang, G.; Yu, D. Two bHLH Transcription Factors, bHLH $_{34}$ and bHLH bu4 $_{104}$ Regulate Iron Homeostasis in Arabidopsis thaliana. Plant Physiol. 2016, 170, 2478-2493. [CrossRef]

17. Cardon, G.; Hohmann, S.; Klein, J.; Nettesheim, K.; Saedler, H.; Huijser, P. Molecular characterisation of the Arabidopsis SBP-box genes. Gene 1999, 237, 91-104. [CrossRef]

18. Li, C.L.; Lu, S.F. Molecular characterization of the SPL gene family in Populus trichocarpa. Biogeochemistry 2014, 14, 131. [CrossRef] [PubMed]

19. Li, X.Y.; Lin, E.P.; Huang, H.H.; Niu, M.Y.; Tong, Z.K.; Zhang, J.H. Molecular Characterization of SQUAMOSA PROMOTER BINDING PROTEIN-LIKE (SPL) Gene Family in Betula luminifera. Front. Plant Sci. 2018, 9, 608. [CrossRef] [PubMed]

20. Cheng, H.T.; Hao, M.Y.; Wang, W.X.; Mei, D.S.; Tong, C.B.; Wang, H.; Liu, J.; Fu, L.; Hu, Q. Genomic identification, characterization and differential expression analysis of SBP-box gene family in Brassica napus. BMC Plant Biol. 2016, 16, 196. [CrossRef]

21. Zhou, Q.; Zhang, S.S.; Chen, F.; Liu, B.J.; Wu, L.; Li, F.; Zhang, J.P.; Bao, M.Z.; Liu, G.F. Genome-wide identification and characterization of the SBP-box gene family in Petunia. BMC Genom. 2018, 19, 1-18. [CrossRef] 
22. Birkenbihl, R.P.; Jach, G.; Saedler, H.; Huijser, P. Functional dissection of the plant-specific SBP-domain: Overlap of the DNA-binding and nuclear localization domains. J. Mol. Biol. 2005, 352, 585-596. [CrossRef] [PubMed]

23. Yamasaki, K.; Kigawa, T.; Inoue, M.; Tateno, M.; Yamasaki, T.; Yabuki, T.; Aoki, M.; Seki, E.; Matsuda, T.; Nunokawa, E.; et al. A novel zinc-binding motif revealed by solution structures of DNA-binding domains of Arabidopsis SBP-family transcription factors. J. Mol. Biol. 2004, 337, 49-63. [CrossRef] [PubMed]

24. Huijser, P.; Schmid, M. The control of developmental phase transitions in plants. Development 2011, 138, 4117-4129. [CrossRef] [PubMed]

25. Xing, S.P.; Salinas, M.; Höhmann, S.; Xing, S.; Berndtgen, R.; Huijser, P. miR156 Targeted and Nontargeted SBP-Box Transcription Factors Act in Concert to Secure Male Fertility in Arabidopsis. Plant Cell 2010, 22, 3935-3950. [CrossRef] [PubMed]

26. Zhang, Y.; Schwarz, S.; Saedler, H.; Huijser, P. SPL8, a local regulator in a subset of gibberellin-mediated developmental processes in Arabidopsis. Plant Mol. Biol. 2007, 63, 429-439. [CrossRef]

27. Wang, Z.; Wang, Y.; Kohalmi, S.E.; Amyot, L.; Hannoufa, A. SQUAMOSA PROMOTER BINDING PROTEIN-LIKE 2 controls floral organ development and plant fertility by activating ASYMMETRIC LEAVES 2 in Arabidopsis thaliana. Plant Mol. Biol. 2016, 92, 661-674. [CrossRef]

28. Bartel, D.P. MicroRNAs: Genomics, biogenesis, mechanism, and function. Cell 2014, 116, 281-297. [CrossRef]

29. Liu, N.; Wu, S.; Van Houten, J.; Wang, Y.; Ding, B.; Fei, Z.J.; Clarke, T.H.; Reed, J.W.; van der Knaap, E. Down-regulation of AUXIN RESPONSE FACTORS 6 and 8 by microRNA 167 leads to floral development defects and female sterility in tomato. J. Exp. Bot. 2014, 65, 2507-2520. [CrossRef]

30. Wang, Y.; Sun, F.L.; Cao, H.; Peng, H.R.; Ni, Z.F.; Sun, Q.X.; Yao, Y.Y. TamiR159 directed wheat TaGAMYB cleavage and its involvement in anther development and heat response. PLoS ONE 2012, 7, e48445. [CrossRef]

31. Li, J.; Guo, G.H.; Guo, W.W.; Guo, G.G.; Tong, D.; Ni, Z.F.; Sun, Q.F.; Yao, Y.Y. miR164-directedcleavage of ZmNAC1 confers lateral root development in maize (Zea mays L.). BMC Plant Biol. 2012, 12, 220. [CrossRef] [PubMed]

32. Feng, H.; Duan, X.Y.; Zhang, Q.; Li, X.R.; Wang, B.; Huang, L.L.; Wang, X.J.; Kang, Z.S. The target gene of tae-miR164, a novel NAC transcription factor from the NAM subfamily, negatively regulates resistance of wheat to stripe rust. Mol. Plant Pathol. 2014, 15, 284-296. [CrossRef] [PubMed]

33. Silva, G.F.F.E.; Silva, E.M.; Da Silva Azevedo, M.; Guivin, M.A.C.; Ramiro, D.A.; Figueiredo, C.R.; Carrer, H.; Peres, L.E.P.; Nogueira, F.T.S. microRNA156-targeted SPL/SBP box transcription factors regulate tomato ovary and fruit development. Plant J. 2014, 78, 604-618. [CrossRef]

34. Cui, L.G.; Shan, J.X.; Shi, M.; Gao, J.P.; Lin, H.X. The miR156-SPL9-DFR pathway coordinates the relationship between development and abiotic stress tolerance in plants. Plant J. 2014, 80, 1108-1117. [CrossRef]

35. Wang, H.; Wang, H. The miR156/SPL module, a regulatory hub and versatile toolbox, gears up crops for enhanced agronomic traits. Mol. Plant 2015, 8, 677-688. [CrossRef] [PubMed]

36. Xu, M.; Hu, T.; Zhao, J.; Park, M.Y.; Earley, K.W.; Wu, G.; Yang, L.; Poethig, R.S. Developmental functions of miR156-regulated SQUAMOSA PROMOTER BINDING PROTEIN-LIKE (SPL) genes in Arabidopsis thaliana. PLoS Genet. 2016, 12, e1006263. [CrossRef] [PubMed]

37. Long, J.M.; Liu, C.Y.; Feng, M.Q.; Liu, Y.; Wu, X.M.; Guo, W.W. miR156-SPLs module regulates somatic embryogenesis induction in citrus callus. J. Exp. Bot. 2018, 69, 2979-2993. [CrossRef]

38. Gou, J.Q.; Fu, C.X.; Liu, S.J.; Tang, C.R.; Debnath, S.; Flanagan, A.; Ge, Y.X. The miR156-SPL4 module predominantly regulates aerial axillary bud formation and controls shoot architecture. New Phytol. 2017, 216, 829. [CrossRef]

39. Shang, M.Y.; Wang, X.T.; Zhang, J.; Qi, X.H.; Ping, A.; Hou, L.P.; Xing, G.M.; Li, G.Z.; Li, M.L. Genetic Regulation of GA Metabolism during Vernalization, Floral Bud Initiation and Development in Pak Choi (Brassica rapa ssp. chinensis Makino). Front. Plant Sci. 2017, 8, 1533. [CrossRef] [PubMed]

40. Zhang, N.; Wen, J.; Zimmer, E.A. Expression patterns of AP1, FUL, FT and LEAFY orthologs in Vitaceae support the homology of tendrils and inflorescences throughout the grape family. J. Syst. Evol. 2015, 53, 469-476. [CrossRef]

41. Dong, B.; Deng, Y.; Wang, H.B.; Gao, R.; Stephen, G.K.; Chen, S.M.; Jiang, J.F.; Chen, F.D. Gibberellic Acid Signaling Is Required to Induce Flowering of Chrysanthemums Grown under Both Short and Long Days. Int. J. Mol. Sci. 2017, 18, 1259. [CrossRef] 
42. Hou, H.; Li, J.; Gao, M.; Singer, S.D.; Wang, H.; Mao, L.; Fei, Z.; Wang, X. Genomic organization, phylogenetic comparison and differential expression of the SBP-box family genes in grape. PLoS ONE 2013, 8, e59358. [CrossRef] [PubMed]

43. Yu, S.; Galvão, V.C.; Zhang, Y.C.; Horrer, D.; Zhang, T.Q.; Hao, Y.H.; Feng, Y.Q.; Wang, S.; Schmid, M.; Wang, J.W. Gibberellin regulates the Arabidopsis floral transition through miR156 targeted SQUAMOSA promoter binding-like transcription factors. Plant Cell 2012, 24, 3320-3332. [CrossRef]

44. Xi, W.; Liu, C.; Hou, X.; Yu, H. MOTHER OF FT AND TFL1 regulates seed germination through a negative feedback loop modulating ABA signaling in Arabidopsis. Plant Cell 2010, 22, 1733-1748. [CrossRef]

45. Hou, X.; Lee, L.Y.; Xia, K.; Yan, Y.; Yu, H. DELLAs modulate jasmonate signaling via competitive binding to JAZs. Dev. Cell 2010, 19, 884-894. [CrossRef]

46. Zhang, Y.Q.; Liu, Z.J.; Wang, L.G.; Sheng, Z.; Xie, J.P.; Bi, Y.R. Sucrose-induced hypocotyl elongation of Arabidopsis seedlings in darkness depends on the presence of gibberellins. J. Plant Physiol. 2010, 167, 1130-1136. [CrossRef]

47. Boccaccini, A.; Santopolo, S.; Capauto, D.; Lorrai, R.; Minutello, E.; Serino, G.; Costantino, P.; Vittorioso, P. The DOF protein DAG1 and the DELLA protein GAI cooperate in negatively regulating the AtGA3ox1 gene. Mol. Plant 2017, 7, 1486-1489. [CrossRef]

48. Zheng, Y.Y.; Gao, Z.P.; Zhu, Z.Q. DELLA-PIF modules: Old dogs learn new tricks. Trends Plant Sci. 2016, 21, 813-815. [CrossRef] [PubMed]

49. Pan, F.; Wang, Y.; Liu, H.L.; Wu, M.; Chu, W.Y.; Chen, D.M.; Xiang, Y. Genome-wide identification and expression analysis of SBP-like transcription factor genes in Moso Bamboo (Phyllostachys edulis). BMC Genom. 2017, 18, 486. [CrossRef] [PubMed]

50. Cai, C.P.; Guo, W.Z.; Zhang, B.H. Genome-wide identification and characterization of SPL transcription factor family and their evolution and expression profiling analysis in cotton. Sci. Rep. 2018, 8, 762. [CrossRef]

51. Finn, R.D.; Bateman, A.; Clements, J.; Coggill, P.; Eberhardt, R.Y.; Eddy, S.R.; Heger, A.; Hetherington, K.; Holm, L.; Mistry, J.; et al. Pfam: The protein families database. Nucleic Acids Res. 2014, 42, 222-230. [CrossRef] [PubMed]

52. Kumar, S.; Stecher, G.; Tamura, K. MEGA7: Molecular evolutionary genetics analysis version 7.0 for bigger datasets. Mol. Biol. Evol. 2016, 33, 1870-1874. [CrossRef] [PubMed]

53. Lu, D.; Wei, W.; Zhou, W.; McGuigan, L.D.; Ji, F.Y.; Li, X.; Xing, Y.; Zhang, Q.; Fang, K.F.; Cao, Q.Q. Establishment of a somatic embryo regeneration system and expression analysis of somatic embryogenesis-related genes in Chinese chestnut (Castanea mollissima Blume). Plant Cell Tissue Organ Cult. 2017, 130, 601-616. [CrossRef] 